\title{
PARAMETRIC ANALYSIS OF MULTI-SPAN \\ CABLE-STAYED BRIDGES UNDER \\ ALTERNATE LOADS
}

2019/14(4)

HIRAM ARELLANO', ROBERTO GOMEZ', DANTE TOLENTINO ${ }^{*}$

${ }^{1}$ Instituto de Ingeniería, Universidad Nacional Autónoma de México, Coyoacán, México

${ }^{2}$ Departamento de Materiales, Universidad Autónoma Metropolitana, CDMX, México

\begin{abstract}
The influence of the stiffness of piers, pylons and deck in the behaviour of multi-span cable-stayed bridges under alternate live loads is analysed. The variation of these parameters is discussed considering both a harp cable system and a fan cable system. Different types of connections between pier-pylon and deck are also considered. Based on the behaviour of a three-span cable-stayed bridge, the variation of pier-pylon stiffness and deck stiffness was analysed. A similar state of stress and deflections was obtained for both a three-span and a multi-span cable-stayed bridge. The study shows that the harp type system presents advantages compared to fan type in terms of its behaviour under alternate live loads considering the same values of deck stiffness and pier-pylon stiffness. It is demonstrated that the resistant mechanism of multi-span cablestayed bridges is provided by the pier-pylon element.
\end{abstract}

Keywords: alternate live loads, cable-stayed bridges, multi-span bridges, pierpylon-deck stiffness.

\footnotetext{
* Corresponding author. E-mail: dantetl@azc.uam.mx
} 


\section{Introduction}

Long-span bridge engineering has had important achievements since the end of the 20th century, mainly due to an increasingly global economic development, an improved theory of bridge design, and better construction methods. Moreover, cable-stayed bridges have proliferated all over the world due to their strong span capability. Along with the fast development of bridge engineering abroad, bridge construction in Mexico has also made significant progress. Mexico has cable-stayed bridges with spans longer than $200 \mathrm{~m}$, such as the Baluarte Bridge, with a main span of $520 \mathrm{~m}$, and the Mezcala Bridge, a multi-span cable-stayed bridge with a main span of $311 \mathrm{~m}$.

The influence of the stiffness parameters of the cables and pylons in cable-stayed bridges has been studied by several authors (Krishna, Arya, \& Agrawal, 1985; O'Connor, 1971; Scalzi, \& Podolny, 1976). Additionally, based on the potential energy analysis of cable-stayed bridges, an extensive parametric study was presented by Hegab (1986). On the other hand, in addition to the stiffness parameters of the cables and pylons, the effect of the bending stiffness of the girder and the unsupported central length of the main span was also studied by Hegab (1988). Wang \& Yang (1996) study the influence of the non-linearity in cable-stayed bridges considering large deflections in beam-column and cable sag effects. The effect of the number of cables and the length of the central span on the behaviour of radiating-type cable-stayed bridges was reviewed by Agrawal (1997).

Although the multi-span cable-stayed bridge is a novel and elegant concept, its structural characteristics are still unclear. With the increase in the number of spans, cable-stayed bridges are becoming more and more flexible. As a result, they are more vulnerable to the action of earthquakes, winds and larger live loads. One problem in the study of multi-span cable-stayed bridges arises when they are analysed under different occurrences of live loads along the bridge defined in this paper as alternate loads. In most cable-stayed bridges with one, two or three spans, the overloads acting in the main span set the cables in tension; such tension is then transmitted through the pylons to the cables anchored at fixed points. In the case of multi-span cable-stayed bridges, self-weight loads or permanent loads are perfectly balanced, even though the central spans lack these fixed points. However, as analysed by Virlogeux (2001), the bridge needs to counterbalance the effect of overloads acting in different spans.

The multi-span cable-stayed bridges have become one of the main structures of modern highways and railways for crossing rivers and straits. The first attempts to understand these structures were made by 
engineers who worked on their design (Arnaud, Matsunaga, Nagano, \& Ragaru, 2008). The following aspects of such bridges have been studied:

- the interaction among elements in cable-stayed bridges (Straupe \& Paeglitis, 2012, 2013);

- the seismic response of a multi-span cable-stayed bridge (Zong, Zhou, Huang, \& Xia, 2014);

- the dynamic characteristics of a cable-stayed bridge using a subspace iteration method (Wang, Chen, Xing, \& Li, 2014);

- the behaviour of multi-span cable-stayed bridges using a parametric analysis (Amiri \& Nakamura, 2015);

- the static and seismic behaviours of a multi-span cable-stayed bridge with three different types of tower, performing an extensive parametric analysis to evaluate the deck-tower interaction in the transverse seismic response (Camara \& Efthymiou, 2016);

- the dynamic response of cable-stayed bridges to the sudden rupture using a parametric study (Mozos \& Aparicio, 2010a, 2010b).

However, the parametric analysis of multi-span cable-stayed bridges under alternate loads has been studied only slightly. Such condition is important because it is possible to generate both unacceptable stresses and deformations in the structural elements, which lead to instability problems in the kind of bridge mentioned.

This paper analyses the influence of the stiffness of piers, pylons and deck on the behaviour of multi-span cable-stayed bridges under alternate loads. The variation of these parameters is discussed considering two configurations for the cable systems, harp and fan, as well as different types of connections between pier-pylon and deck. Moreover, the behaviour of a three-span cable-stayed bridge is analysed until a similar state of stresses and deflections between the three-span cable-stayed bridge and a multi-span cable-stayed bridge is obtained.

\section{Bridge model description}

A comparative study of both harp and fan types of multi-span cablestayed bridges was carried out using a bridge model with five spans and four pylons. The length of the main span is $200 \mathrm{~m}$, and the side span is $100 \mathrm{~m}$. 2D Structural models were developed with SAP2000 v9 software (SAP2000 Advanced 9.0.0), using the only bar and cable elements. A symmetrical layout of cables was assumed, with a $9 \mathrm{~m}$ separation on the deck among them; the two cables located in the centre of the main span are $20 \mathrm{~m}$ apart. A tri-cellular box section of concrete with two
Parametric Analysis

of Multi-Span

Cable-Stayed

Bridges under

Alternate Loads 

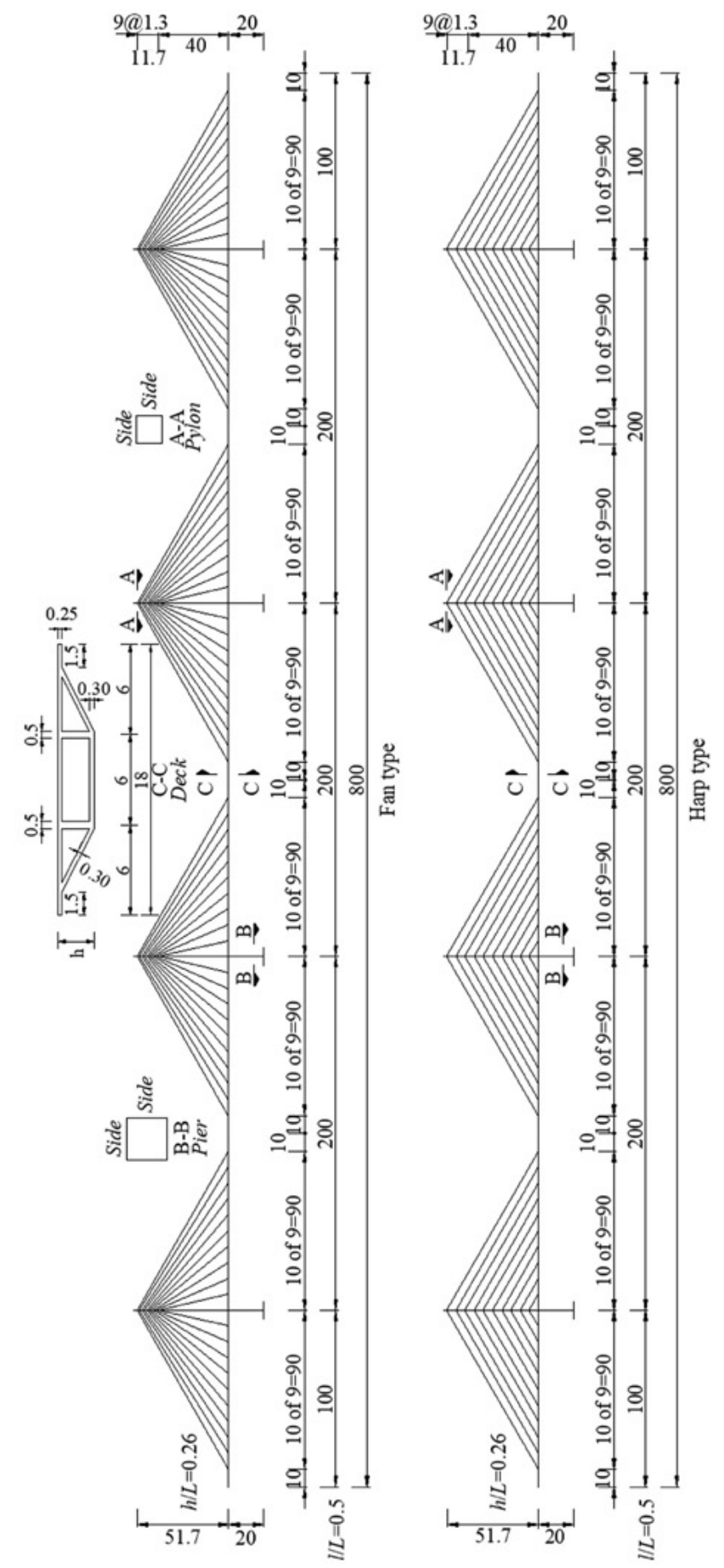

Figure 1. The geometry of cable-stayed bridge for fan and harp type 


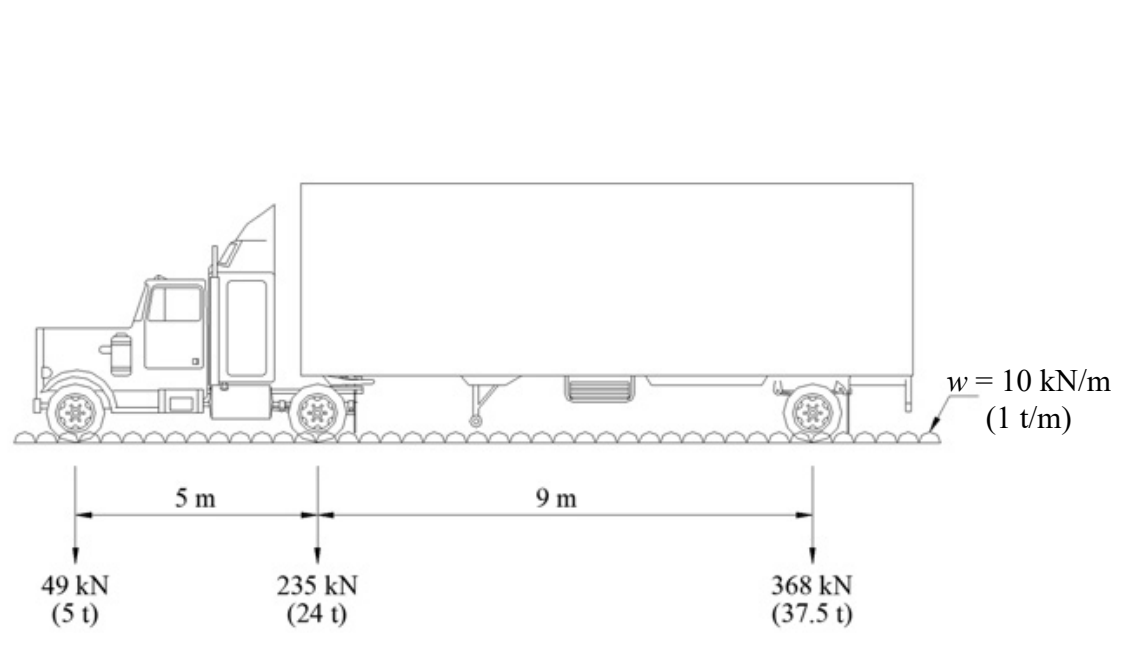

a) IMT 66.5 live load model

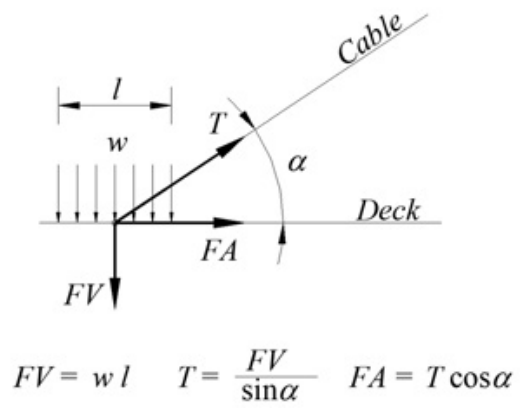

b) diagram of the force equilibrium method

Figure 2. For three types of connection

vertical webs, two inclined webs, and a total width of $18 \mathrm{~m}$ was used. The thickness of the top slab, bottom slab, vertical webs and inclined webs are $0.25 \mathrm{~m}, 0.30 \mathrm{~m}, 0.5 \mathrm{~m}$ and $0.30 \mathrm{~m}$, respectively. The height is constant throughout its length. Piers and pylons have been modelled with solid sections of concrete.

The thickness of the diaphragms was $0.5 \mathrm{~m}$; the distance among diaphragms was $4.5 \mathrm{~m}$; the asphalt thickness was $0.12 \mathrm{~m}$, and the weight of the parapets was $0.6 \mathrm{t} / \mathrm{m}$. Figure 1 shows the geometry of the two types of models considered. The live load denoted as IMT 66.5 (Secretaría de Comunicaciones y Transportes, 2001) was used. The IMT 66.5 consists of a point loads of $49 \mathrm{kN}(5 \mathrm{t}), 235 \mathrm{kN}$ (24 t) and $368 \mathrm{kN}(37.5 \mathrm{t}$ ) with a distance between the first and second loads of $5 \mathrm{~m}$ and $9 \mathrm{~m}$ between the second and third loads. In addition, the model considers a uniformly distributed load of $10 \mathrm{kN} / \mathrm{m}(1 \mathrm{t} / \mathrm{m})$ over the entire length of the truck (Figure 2a). It is important to mention that the IMT 66.5 model is similar to the fatigue load model 2 used in EN 1991-2:2003. 
Eurocode 1: Actions on Structures - Part 2: Traffic Loads on Bridges. The impact was also considered, and the alternate overload was applied on the first, third and fifth spans to generate a symmetrical stress distribution. For the design of the cable cross-sections, it was assumed that each of them supports $9 \mathrm{~m}$ of the deck, with their corresponding dead loads (self-weight and diaphragms) and service dead loads such as the weight of both asphalt and parapets. Tensions were calculated for each cable and the two types of cable systems using the force equilibrium method (Chen, Au, Tham, \& Lee, 2000) (Figure 2b), and working stresses at 0.45 breaking strength in accordance to Service d'Etudes Techniques des Routes et Autoroutes (SETRA) (2001).

\section{Pier-pylon and deck connection types}

There are three types of connections between pier-pylon and deck that are used in cable-stayed bridges. Type 1 occurs when the cables support the deck without any intermediate support, and the pylon is embedded in the pier. Type 2 is where the pylon is embedded in the deck, supported on the pier; connection type 3 is achieved when the deck is rigidly embedded at both the top of the pier and the bottom of the pylon. Figure 3 shows the three types of connections considered here.

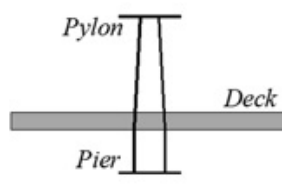

a) Type 1

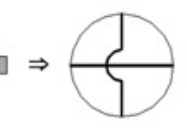

-

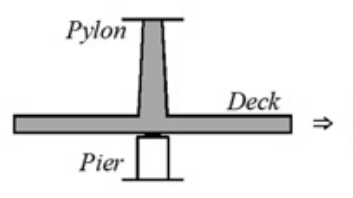

b) Type 2

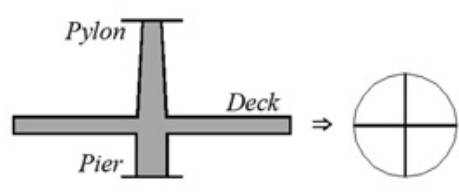

c) Type 3

Figure 3. Pier-pylon and deck connection types

\section{Parameters considered}

The stiffness of both pier-pylon and deck are the only parameters considered here. Four types of decks were used T-1, T-2, T-3 and T-4; their geometric properties are shown in Table 1. It is important to point out that the geometric properties increase as the number of type case increases. Four types of pier-pylon dimensions were considered as well: P-1, P-2, P-3 and P-4 (Table 1). In total, 16 models were generated for each cable system. 
Table 1. Properties of deck, pier and pylon cross-sections

\begin{tabular}{cccccr}
\hline Element & Type & $\begin{array}{c}\text { Height, Side* } \\
\mathbf{m}\end{array}$ & $\begin{array}{c}\text { Area } \\
\mathbf{m}^{\mathbf{2}}\end{array}$ & $\begin{array}{c}\text { Centroid } \\
\mathbf{m}\end{array}$ & $\begin{array}{r}\text { Moment } \\
\text { of inertia } \\
\mathbf{m}^{4}\end{array}$ \\
\hline Deck & T1 & 1.00 & 11.0750 & 0.4832 & 1.4086 \\
& T2 & 1.50 & 12.0750 & 0.7175 & 4.0017 \\
& T3 & 2.00 & 13.0750 & 0.9543 & 8.0992 \\
& T4 & 2.50 & 14.0750 & 1.1929 & 13.827 \\
\hline Pylon & P1 & 3.00 & 9.0000 & 1.5000 & 6.7500 \\
& P2 & 4.00 & 16.0000 & 2.0000 & 21.3330 \\
& P3 & 5.00 & 25.0000 & 2.5000 & 52.0833 \\
& P4 & 6.00 & 36.0000 & 3.0000 & 108.0000 \\
\hline Pier & P1 & 4.00 & 16.0000 & 2.0000 & 21.3333 \\
& P2 & 5.50 & 30.2500 & 2.7500 & 76.2552 \\
& P3 & 7.00 & 49.0000 & 3.5000 & 200.0833 \\
& P4 & 8.50 & 72.2500 & 4.2500 & 435.0052 \\
\hline
\end{tabular}

Note: * - for Pylon and Pier.
Parametric Analysis of Multi-Span

\section{Results of the comparative study}

The results obtained from the structural analysis of each model studied were obtained for the alternate overload acting on different spans. Two representative aspects of deck behaviour are studied: vertical deflection and axial force. Moreover, the behaviour of the pierpylon is evaluated in terms of both the longitudinal deflection and the bending moment.

\subsection{Deflection and axial force in the deck}

The vertical deflection at the main span of the deck for the harp-type cable system results lower than the deflection of the fan type system. It is observed that the deflections of cable systems T-1 and T-2 increase as the stiffness of the pier-pylon increases. Such increment is small for the case of the lowest stiffness in the deck (Figure 4a). However, these differences are less than 7\%. Moreover, the difference of deck deflections among the types of cable systems decreases as the stiffness of the deck increases. Such a difference is greater than the one obtained when increasing the pier-pylon stiffness. The fact that the difference is significant for all cases means that the pier-pylon stiffness presents 
more influence on the difference of deck deflections among the two types of cable systems.

The distribution of the axial force in the deck is shown in Figure $4 \mathrm{~b}$. It is noticed that the harp-type provides axial forces greater than the fan type. It is possible to associate such difference to the smaller angle of the cable to the horizontal for the same vertical load. For the same type of deck, an increase of the pier-pylon stiffness results in an increase of compression forces on the extreme piers, and a decrease of compressions or tensions in the vicinity of the central piers. Such an increase in tension in the main span and around its two adjacent piers is because the increase of pier-pylon stiffness decreases their deformation. Increasing the load on the cables induces tension forces in the loaded main span. Thus, an increase of compressions around the side piers is generated.

The difference in the tension forces of the lateral spans between the harp-type and fan-type becomes lowest as the pile-pylon stiffness increases, in concordance with the trend of the vertical deflections of the deck. Moreover, it is observed that the compressions around the extreme piers decrease as the stiffness of the deck increases for both types of cable systems. Such increase provokes a reduction in its vertical deflection. As a consequence, the tension force in the cable decreases the axial compression forces at the deck. The following behaviours are noticed at the main span:

- the axial force is different because it is in tension in both sides;

- such axial force increases as the deck stiffness increases;

- the differences of the axial forces for the different types of cable systems increase as a function of the increment of the deck stiffness, reaching a maximum of $24 \%$ for the lowest deck stiffness.

In all cases, the harp-type cable system has the greatest axial force in the vicinity of the piers, and the smallest in the main span. The differences increase when the highest stiffness in the deck and the lowest stiffness in the pier-pylon are present.

\subsection{Longitudinal deflection and bending moment of the pier-pylon}

For all cases, the longitudinal deflection of the upper part of the pylon is bigger for the fan type than for the harp type system, as shown in Figure 5. The less efficiency of the pylon in the fan type is due to the geometry of the system: the fan type system has the cables anchored in the upper part, whereas the harp system has the cables distributed throughout the height of the pylon. For a pier-pylon with P1 and P2 stiffness, when the stiffness of the deck increases, the difference 


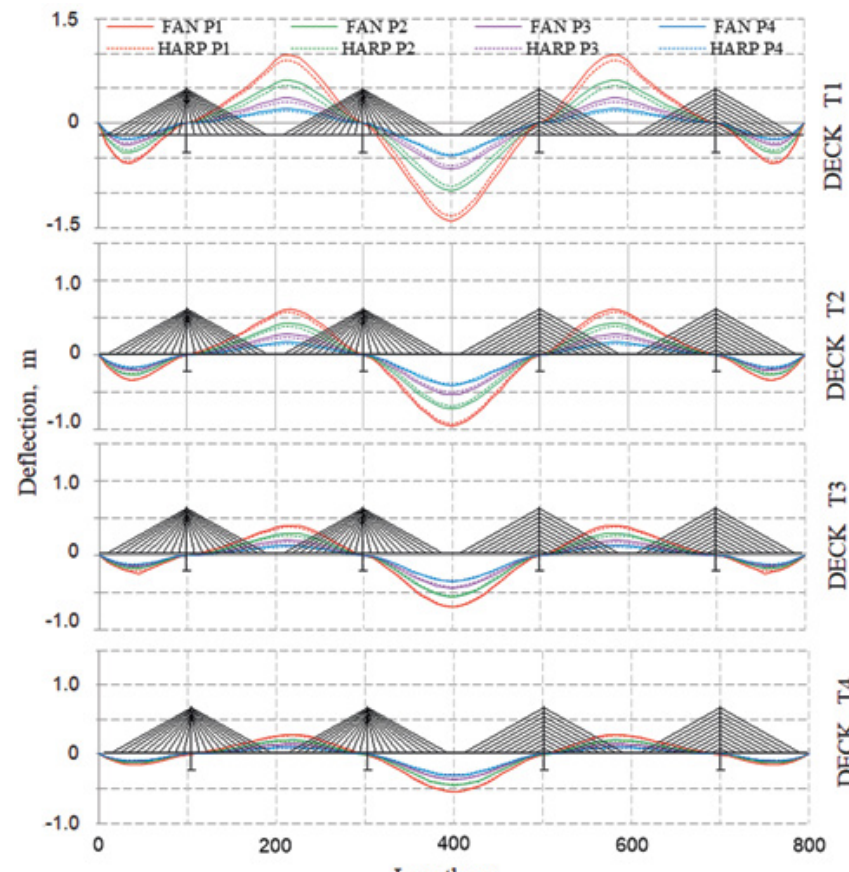

Length, $m$

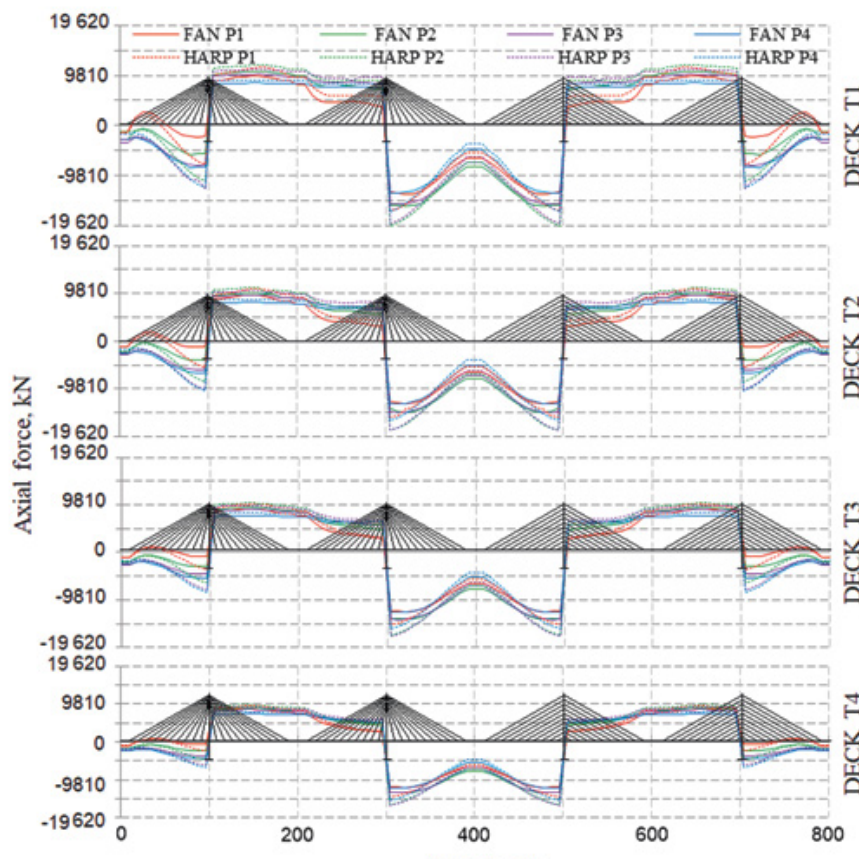

Length, $m$
Parametric Analysis of Multi-Span

Cable-Stayed

Bridges under

Alternate Loads

a) Deck deflection

Figure 4. Comparison for both cable system types 

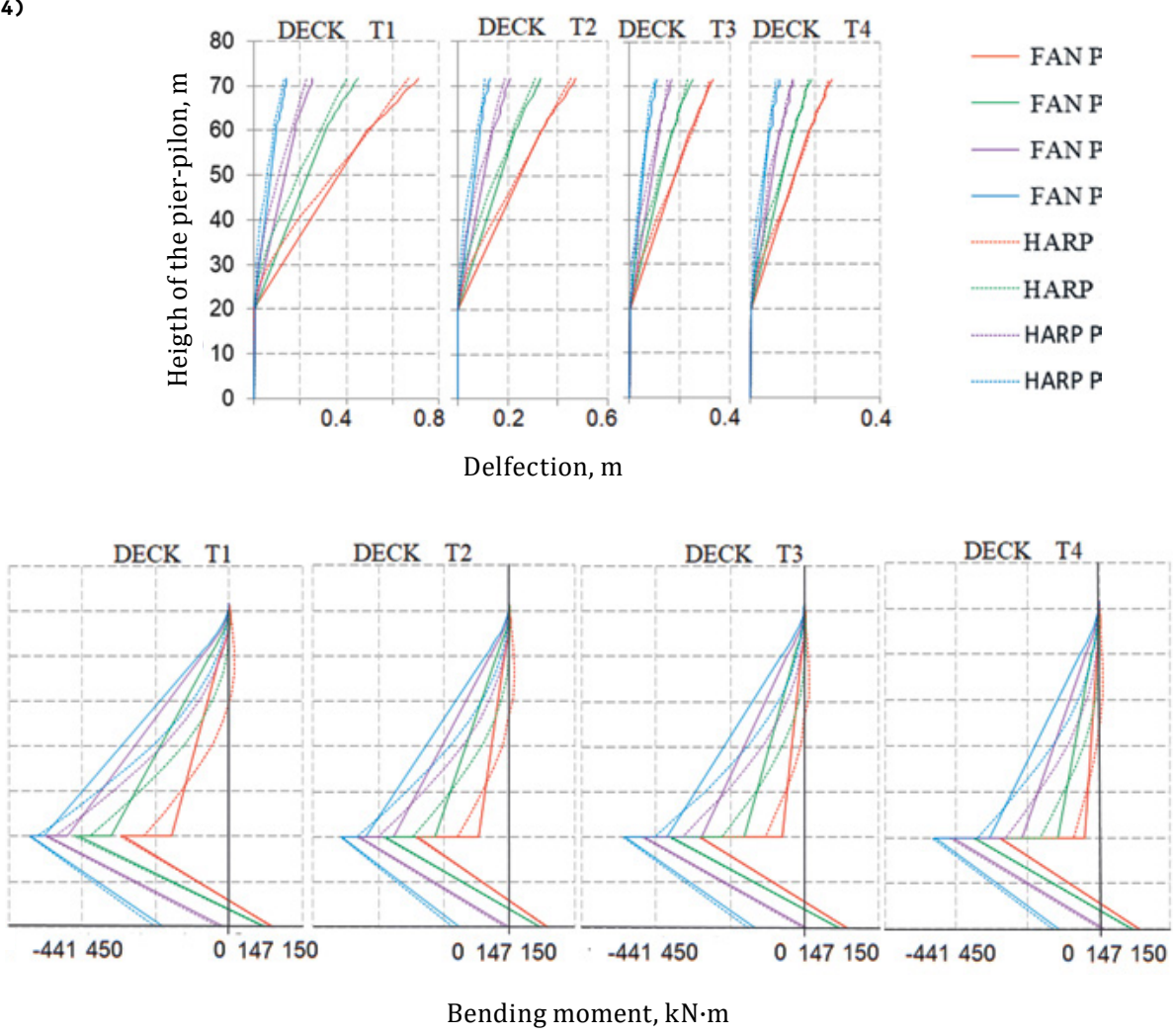

Figure 5. Comparison of deflections and bending moments in pier-pylon for two types of the cable system

between the longitudinal deflection of the harp-type and the fan-type decreases. However, for the case of P3 and P4 pier-pylon stiffness, the trend is unclear. On the other hand, for the T- 3 and T- 4 deck stiffness, the difference between the two models increases when the stiffness of the pier-pylon increases. Such difference decreases for the lowest T-1 and T-2 deck stiffness.

Figure 5 shows how the bending moment for the pile-pylon are different for the two types of the system due to the different distribution of tension forces in the cables along with the pylon; a bending moment of the linear type is generated for the fan system and parabolic for the harp-type. In all cases, it is observed that the bending moments at the base of the pylon present high values for the harp-type; such bending moments decrease with the height of the pylon. The bending moment 
at the bottom of the pylon is proof of the important contribution of the pier in the effectiveness of the harp-type. It was also observed that the bending moments decrease at the bottom of the pier as the deck stiffness increases because both the deflection of the deck and the tensions that the cables transmit to the piers are lower. On the other hand, if the stiffness of the pier increases, the bending moment increases because the pier deflection is less; the tension force that the cables transmit to the pier increases as well.

\section{Parametric analysis}

Having reviewed the variation of each element stiffness for multi-span cable-stayed bridges as a function of its cable system, the stiffness of each element for the different types of connection is presented below. Such analysis is performed by measuring the increase of the stiffness until a similar state of both stresses and deflections between a three-span cable-stayed bridge and multi-span cable-stayed bridge is obtained. A harp-type with three spans is used for the parametric analysis; the central span is $200 \mathrm{~m}$, and both lateral spans are $100 \mathrm{~m}$ each. Such bridge was designed to resist demands of dead and service loads, as well as additional overloads on the main span. The multi-span bridges were generated with the same crosssections for the deck and pier-pylon. Results of the three-span base model presented above for the three different types of connection between pier-pylon and deck were taken into account. The generated models allowed measuring the deficiencies of the intermediate pylons of the multi-span cable-stayed bridges, in contrast with the pylons of the three-span bridges with fixed points, which limit their deformation.

\subsection{Deficiencies of multi-span cable-stayed bridges}

A direct comparison between three and five-span bridge models was performed, considering the same deck and pier-pylon stiffness. Considerable differences in their behaviour were noticed. Therefore, it is possible to identify the deficiencies presented by the multi-span cable-stayed bridges from a general point of view. For connection types 1 and 3, the deflection of the deck at the centre of the main span in both models is $60 \%$ more for the case of the five-span bridge. For the type 2 connection, the difference increases up to $100 \%$ because the deflection of the deck completely neglects the pier stiffness. 
The five-span bridge deflects more than the three-span bridge due to the lack of anchor points at the intermediate pylons. For the case of the five-span bridge, the axial compression force in the main span is less than the three-span bridge, for all types of connection. However, the axial forces of tension in contiguous spans are higher for the five-span bridge than for the three-span bridge. The difference is produced by both the tension in the cables on the main span and the compression force induced by the cables of the contiguous spans.

The bending moments in the deck for connection types 1 and 3 are more significant in the cases of five spans than the bridges of three spans. For the maximum negative $(-)$ and positive $(+)$ moments, the differences are $26 \%$ and $59 \%$, respectively. For the type 2 connection, the differences increase up to $216 \%$ for positive moment and a decrease of $11 \%$ in the case of a negative moment. Consequently, the outer cables of the main span of the five-span bridges are less loaded than those of the three-span bridges, whereas the inner cables are loaded much more because the outer cables are anchored closer to the tip of the pylon. In

Table 2. Comparison of results among three and five-span bridges for three types of connection

\begin{tabular}{|c|c|c|c|c|c|c|c|c|}
\hline \multirow{3}{*}{ 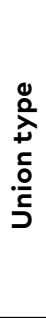 } & \multirow{3}{*}{$\begin{array}{l}\frac{n}{0} \\
\frac{0}{2} \\
\frac{0}{2}\end{array}$} & \multicolumn{4}{|c|}{ Deck in the main span } & \multicolumn{3}{|c|}{ Pylons of the main span } \\
\hline & & 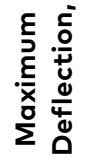 & 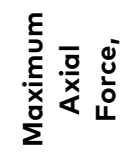 & 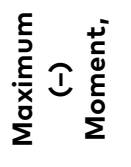 & 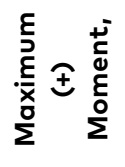 & 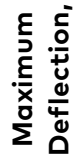 & 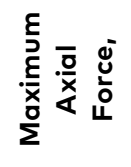 & 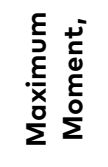 \\
\hline & & m & $\mathbf{k N}$ & $\mathrm{kN} \cdot \mathrm{m}$ & $\mathrm{kN} \cdot \mathrm{m}$ & $\mathbf{m}$ & $\mathbf{k N}$ & $\mathrm{kN} \cdot \mathrm{m}$ \\
\hline \multirow{4}{*}{1} & 3 Spans & 0.84 & -20523 & 22229 & 16775 & 0.35 & -10153 & 119692 \\
\hline & 5 Spans & 1.33 & -16638 & 27949 & 26742 & 0.68 & -8957 & 169576 \\
\hline & Difference & & & & & & & \\
\hline & $\%$ & 159 & 81 & 126 & 159 & 194 & 88 & 142 \\
\hline \multirow{4}{*}{2} & 3 Spans & 1.17 & -10408 & 6426 & 15304 & 0.54 & -11232 & 69298 \\
\hline & 5 Spans & 2.39 & -8986 & 5739 & 33128 & 1.29 & -9928 & 61479 \\
\hline & Difference & & & & & & & \\
\hline & $\%$ & 204 & 86 & 89 & 216 & 239 & 88 & 89 \\
\hline \multirow{4}{*}{3} & 3 Spans & 0.84 & -20523 & 22269 & 16775 & 0.35 & -10153 & 119692 \\
\hline & 5 Spans & 1.33 & -16638 & 27949 & 26742 & 0.68 & -8957 & 169576 \\
\hline & Difference & & & & & & & \\
\hline & $\%$ & 158 & 81 & 126 & 159 & 194 & 88 & 142 \\
\hline
\end{tabular}


the bridge of three spans, these cables are attached to a fixed point. Therefore, the differences of deformations among the outer cables of the two bridges are greater than among the internal cables, because the load on the cables increases with the deformation of the deck and decreases with the deformation of the pylon.

In the longitudinal deflection of the pylon, the bridge of three spans has smaller deformations than the five-span bridge. Such deformations, which are approximately half the magnitude of the displacement in the three types of connection, show the importance of the cable that anchors the pylon to the abutment on the bridge of three spans. A similar case is presented for the bending moment in the pier-pylon, which depends directly on the deflection. However, the axial force in the pylon decreases for the case of the five-span bridge, due to an increase in deflection. The results of the comparison of the values of the parameters in the centre of the main span of the two models are shown in Table 2. The comparison of the three types of connection between pier-pylon and deck is also shown. It is noticed that the deformations and the mechanical elements in the pylon and the deck are the same between connection types 1 and 3 . In case of the deck, the section results with a stiffness that it limit the deformation at the centre of the span when the type 3 of connection is considered. However, it is possible to obtain differences among these types of connections in the case to design a deck with high dimensions. In the case of the pylons, the same deformations and mechanical elements are since both types of connections are embedment in the piers.

\subsection{Increment of pier-pylon stiffness}

To both solve the deficiencies of the five-span bridges, and have a behaviour similar to the three-span bridge, stiffness of the pier-pylon is increased. Then, the influence on the behaviour of the multi-span cable-stayed bridges is determined. Such behaviour also depends on the type of connection between pier-pylon and deck. First, the pier-pylon stiffness was increased to achieve the same deformation of the deck in both models of bridges (three and five spans). For the case of the type 1 connection, increasing six times the pier-pylon stiffness to achieve the same deflection is necessary. For the type 2 connection, changes in deck deflection due to the increment of the pier-pylon stiffness are negligible (Figure 6). The behaviour is similar for types 1 and 3.

In Figure 7, the axial forces on the deck under alternate loads are represented with a positive sign (compression force), and the tension force with a negative sign. For connection types 1 and 3, when 

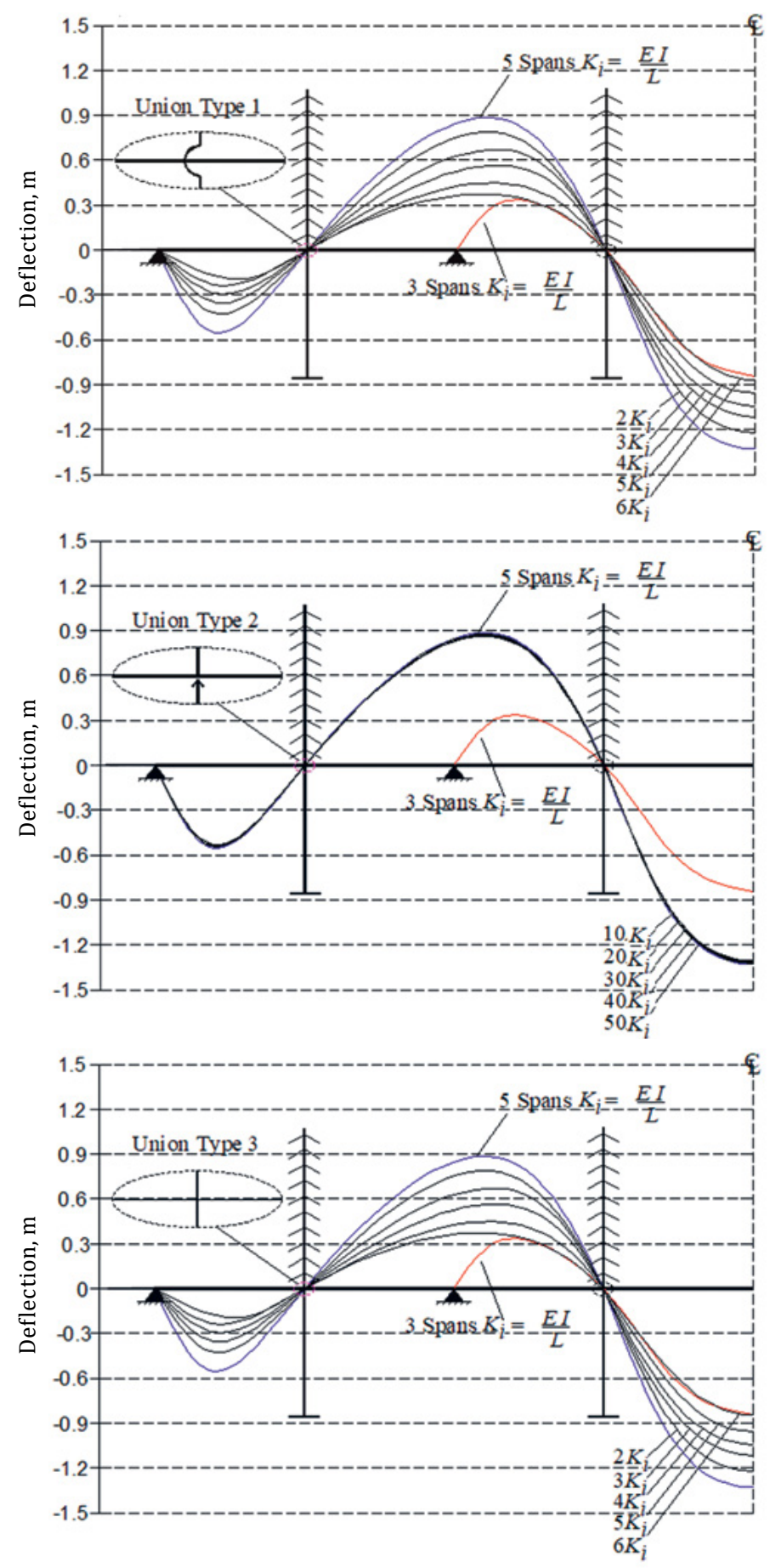

Figure 6. Influence of the pier-pylon stiffness in the deflection of the deck 


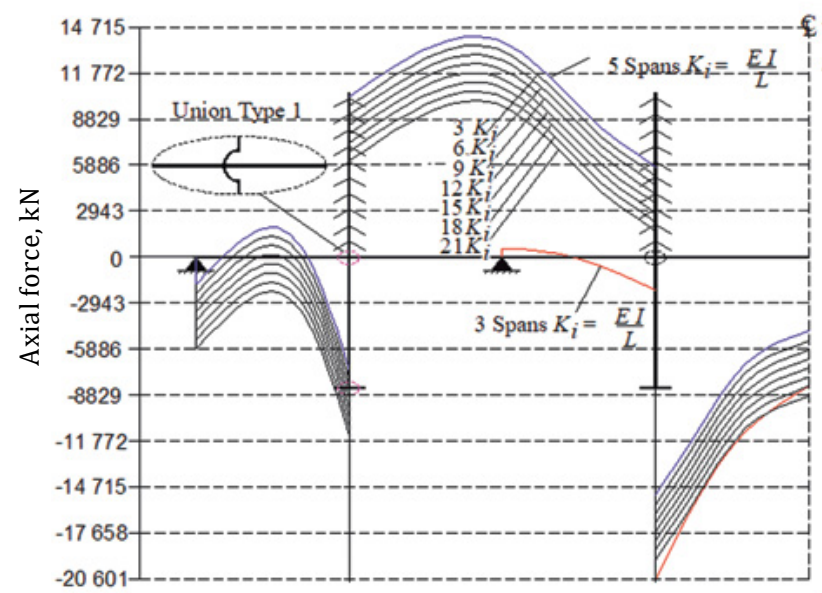

Parametric Analysis of Multi-Span

Cable-Stayed

Bridges under Alternate Loads
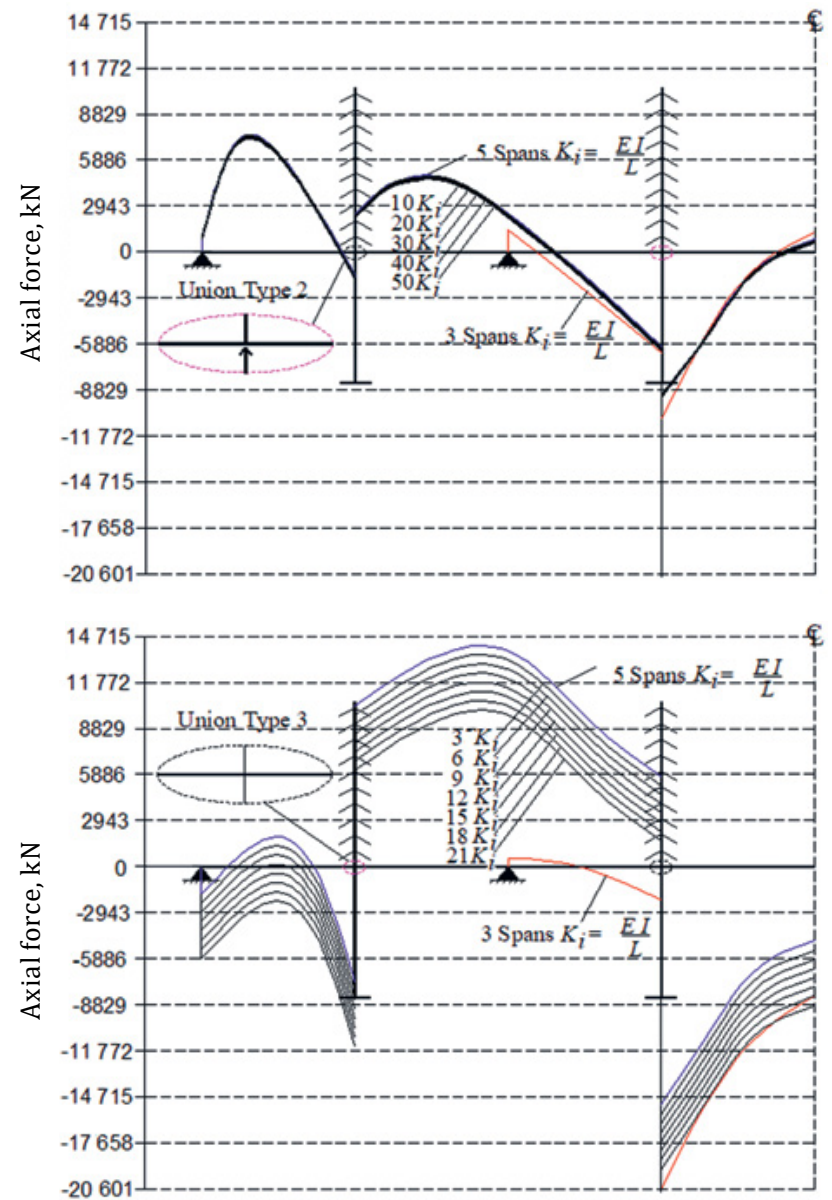

Figure 7. Influence of the pier-pylon stiffness in the axial force of the deck 

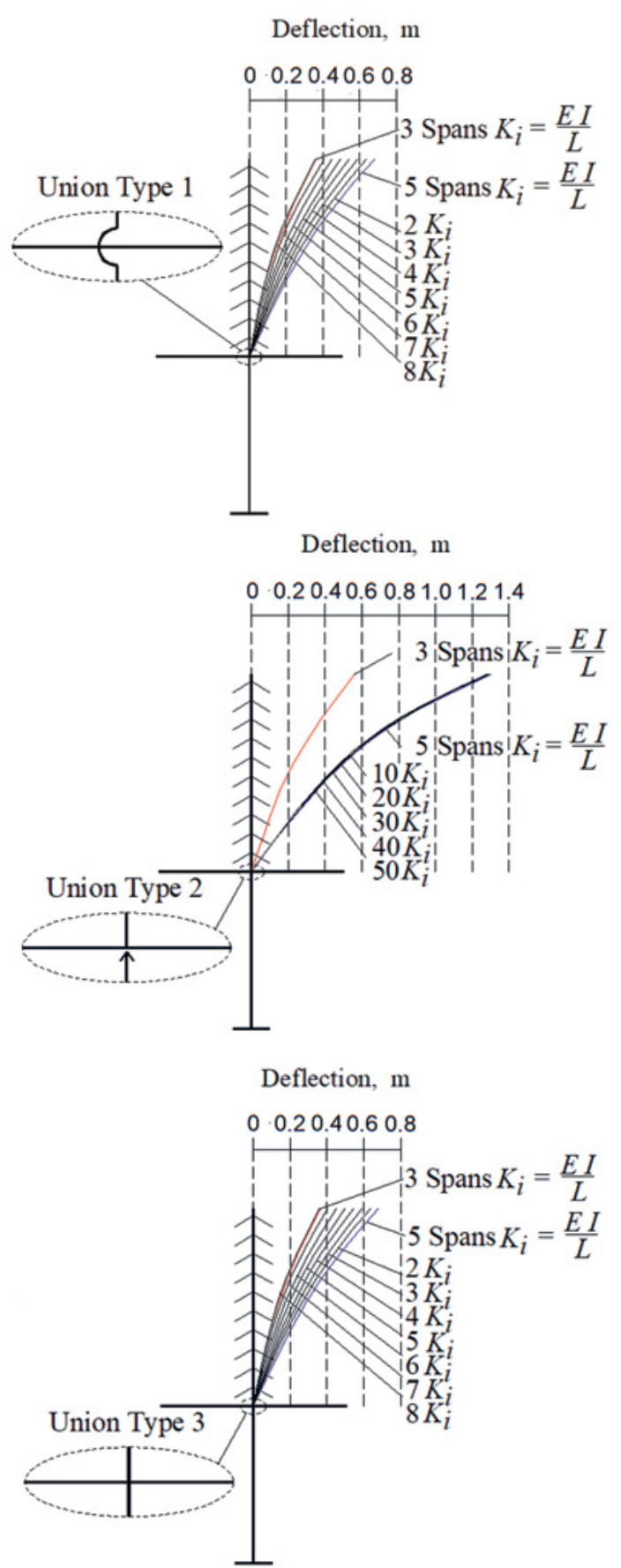

Figure 8. Influence of the pier-pylon stiffness in the longitudinal deflection of the pylon 
the pylon stiffness becomes infinite, the cables of the central and Parametric Analysis of Multi-Span lateral spans only balance the spans, and reduce the compressions, maximising the tension in the deck. Thus, the pylon deflection, which transfers tension to the cables of the contiguous span, provoking both an increase in the tension forces of the deck in that span, and a decrease in the compression forces in the main span. For the type 2 connection, the axial forces are of compression for almost all the bridge of three spans, and practically the same in the central zone of the five-span bridge. Even though there is an increase of the stiffness in the pier-pylon in the type 2 connection, the structural behaviour stays the same. Moreover, when the stiffness of the pier-pylon is increased, the bending moment in the deck shows the same behaviour than the deflection of the deck, as it is expected.

Regarding the behaviour of the pylon, it is possible to reduce the displacement at the tip of the pylon when the stiffness is increased in connection types 1 and 3 . However, for the type 2 connection, in that, the pylon is embedded in the deck. It is noticed that the deflection diagram is practically independent of the pylon stiffness (Figure 8), as described in the behaviour of the deck.

\subsection{Increment of deck stiffness}

The effects of an increment of the deck stiffness are studied in this section to identify the deficiencies of the bridges of five spans and achieve an approximate and similar behaviour to a bridge of three spans. For type 1 connection, if the deck stiffness is increased three times, a deck deflection of $0.93 \mathrm{~m}$ is obtained in the five-span bridge. Whereas for the three-span bridge model of reference, a deflection of $0.84 \mathrm{~m}$ is obtained. When using a type 2 connection, the increase of the deck stiffness reduces its deflection. In case that the stiffness deck increases ten times respect to the reference model, the deck deflection is $1.28 \mathrm{~m}$, that is very close to the reference model, $1.17 \mathrm{~m}$ (Figure 9). For the type 3 connection, increasing the deck stiffness three times reduces the deformation from $1.33 \mathrm{~m}$ to $0.86 \mathrm{~m}$. Thus, the efficiency of the increase of deck stiffness is less than the efficiency of the increase of pier-pylon stiffness.

For type 1 connection, there is a small increase in the axial compression force of the deck when its stiffness is increased. When the deck stiffness is increased six times, a decrease of only $10 \%$ of the axial force on the deck is obtained. For the type 2 connection, it is found that the axial forces of compression decrease on the model of five spans, because the load on the cables is lower, as well as the deflection in the deck. 

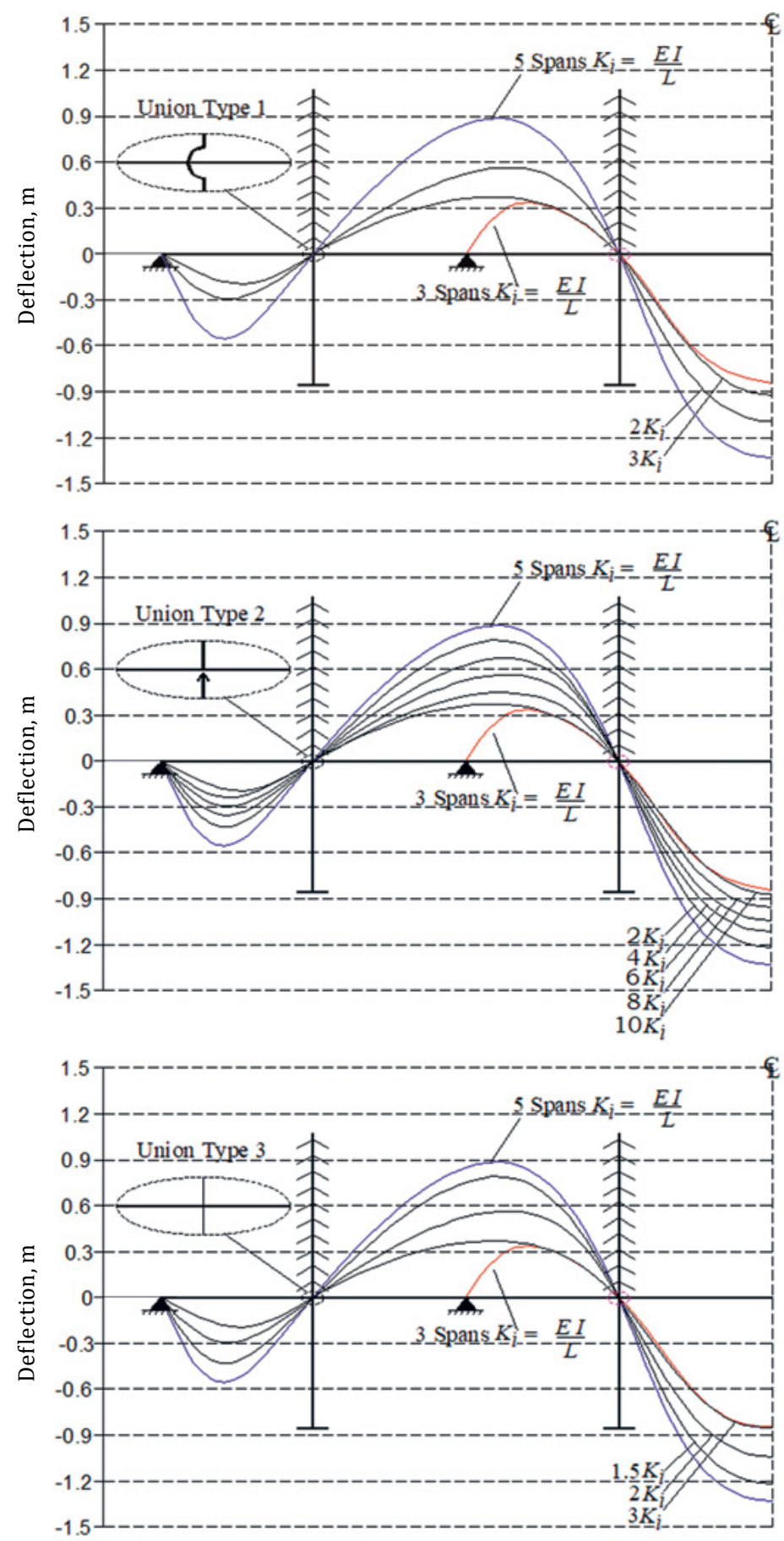

Figure 9. Influence of the deck stiffness in the deflection of the deck 


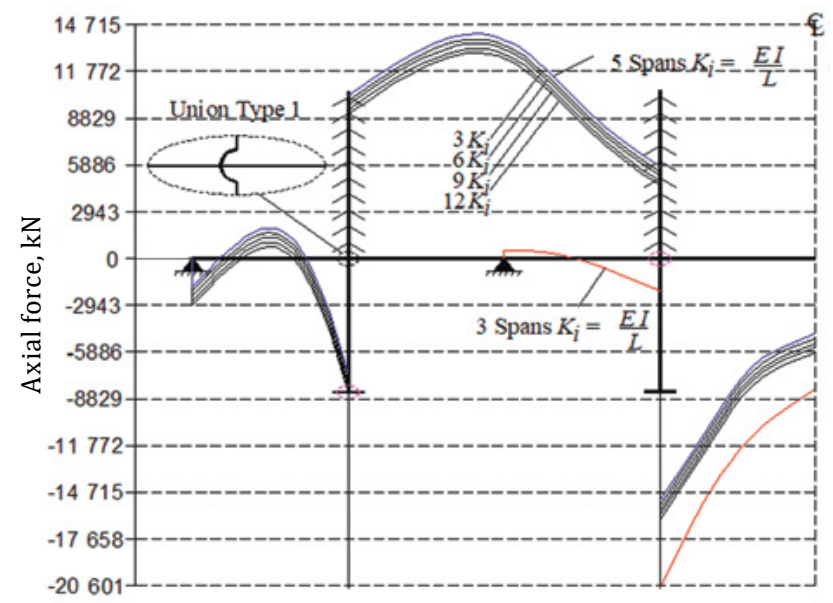

Parametric Analysis of Multi-Span

Cable-Stayed

Bridges under Alternate Loads
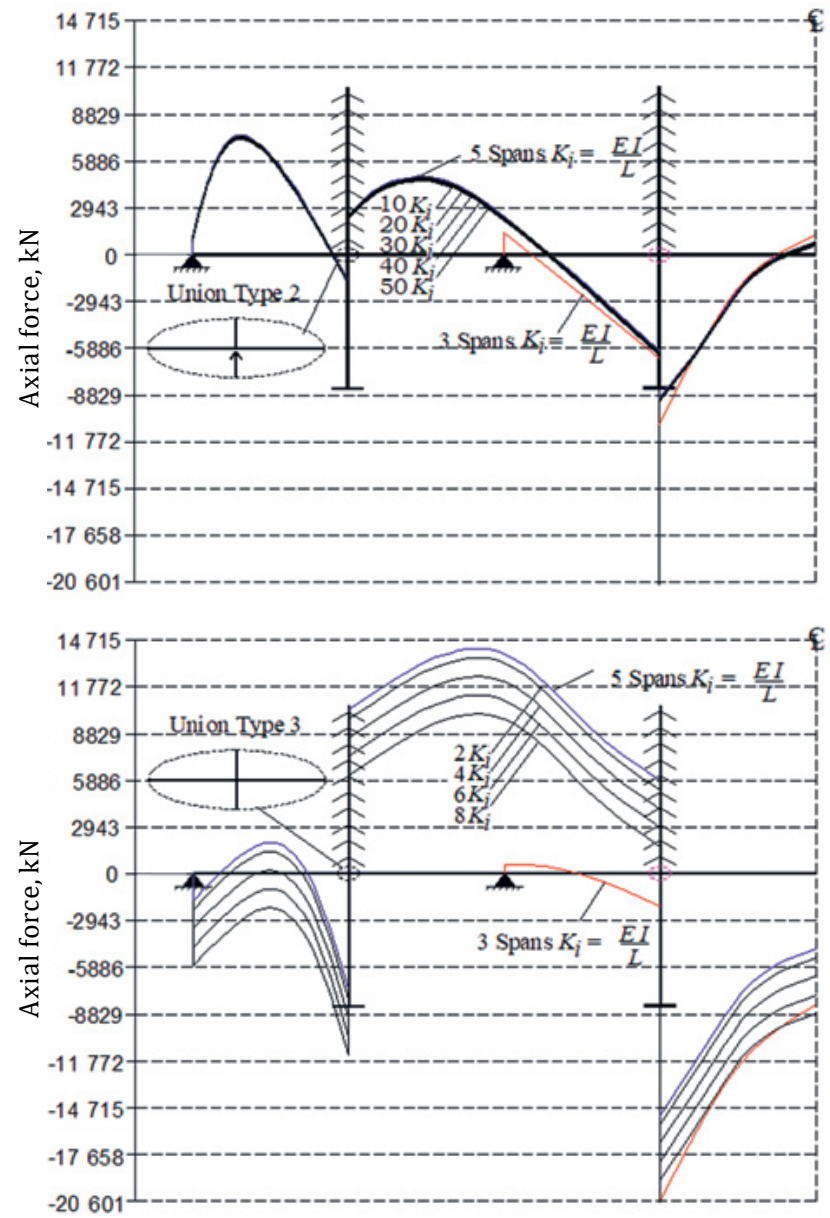

Figure 10. Influence of the deck stiffness in the axial force of the deck 
For the case of alternate live loads at the centre of each span, there are no axial forces due to the following reasons:

a) the bridge only has fixed points in the abutments to constrain the horizontal displacement,

b) there are no horizontal reactions in the piers, and

c) the tension forces on cables on one side are balanced with those on the other side.

For a type 3 connection, there is also a decrease in tensile and compressive stresses in the deck, due to the small deformation of the pier-pylon by the action of a rigid deck. Figure 10 shows how the compression forces in the main span of the five-span bridge with a high deck stiffness become very similar when the initial stiffness is increased six or seven times. The results for the three types of connection are shown.

For connection type 1, the variation of deck stiffness on the pylon behaviour reduces the deflection of the pylon head to $0.33 \mathrm{~m}$ when the deck stiffness is increased six times. Furthermore, for a type 2 connection, if the deck stiffness increases more than twelve times, its deformation decreases, together with the rotation of the pylon. Its longitudinal deflection of the pylon is similar to the case of a threespan bridge with a value of $0.61 \mathrm{~m}$. Figure 11 shows that, for the type 3 connection, an increase of six times in the deck stiffness produces a pylon deflection at the tip of $0.30 \mathrm{~m}$, that is smaller than the reference model of a three-span bridge $(0.35 \mathrm{~m})$.

\subsection{The behaviour of multi-span cable-stayed bridges for different height of piers}

The impact of increasing the pier height on the behaviour of multi-span cable-stayed bridges for different types of pier-pylondeck connection is analysed in the following paragraphs. Increments vary from 0.4 to 1.0 times the original pylon height. For all types of connection, an increment in the deck deflection was observed when compared to the short pier. The effect mentioned is produced by the flexibility of the tall pier, that leads to increasing the stiffness of either the pier-pylon or the deck in higher proportion to reach the values of the three-span bridge. It was also observed that an increase in the pier-pylon stiffness in a five-span bridge with tall pier results in an increase in the tension forces of the cable stays of the central span. Such an increase is much more considerable than in the case of a short pier because it has a tensile state similar to a three-span bridge.

The longitudinal deflection of pylon shows the same trend as the case of a short pier, but the deflection is bigger in case of the tall pier. 
Deflection, $\mathrm{m}$

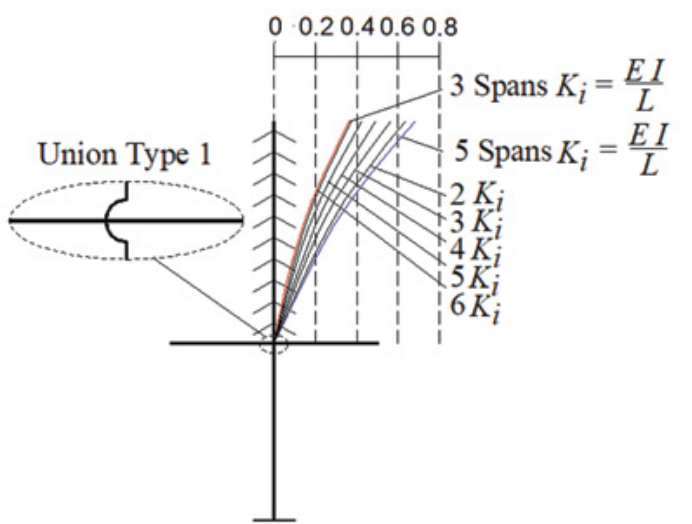

Deflection, $\mathrm{m}$

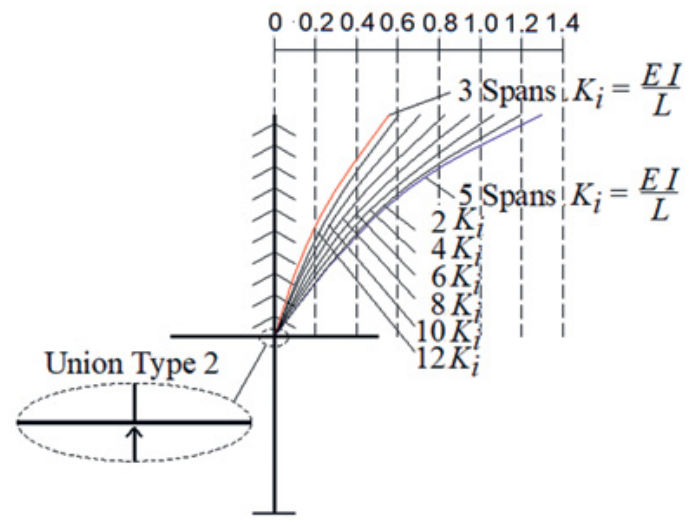

Deflection, $\mathrm{m}$

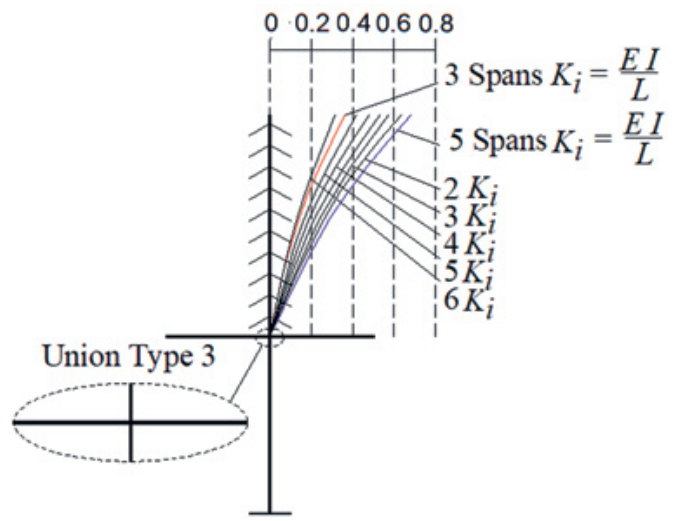

Parametric Analysis of Multi-Span

Cable-Stayed Bridges under Alternate Loads

Figure 11. Influence of the deck stiffness in the longitudinal deflection of the pylon 


\begin{tabular}{|c|c|c|c|c|c|c|c|c|}
\hline \multirow{3}{*}{ 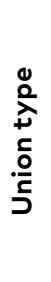 } & \multirow{3}{*}{$\begin{array}{l}\frac{n}{0} \\
\frac{0}{0} \\
\frac{0}{2}\end{array}$} & \multicolumn{4}{|c|}{ Deck in the main span } & \multicolumn{3}{|c|}{ Pylons of the main span } \\
\hline & & 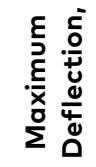 & 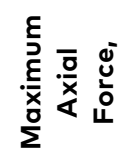 & 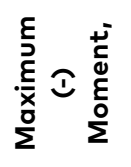 & 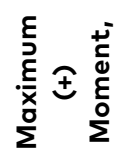 & 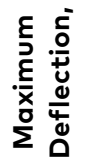 & 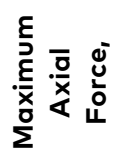 & 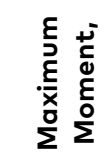 \\
\hline & & m & $\mathbf{k N}$ & $\mathrm{kN} \cdot \mathrm{m}$ & $\mathrm{kN} \cdot \mathrm{m}$ & m & $\mathbf{k N}$ & $\mathrm{kN} \cdot \mathrm{m}$ \\
\hline \multirow{3}{*}{1} & Tall pier & 1.42 & -13136 & 26163 & 27282 & 0.72 & -9025 & 156479 \\
\hline & $\begin{array}{l}\text { Short } \\
\text { pier }\end{array}$ & 1.33 & -16638 & 27949 & 26742 & 0.68 & -8957 & 169576 \\
\hline & $\begin{array}{c}\text { Increase } \\
\%\end{array}$ & 7.00 & -21 & -6 & 2 & 7 & 1 & -8 \\
\hline \multirow{3}{*}{2} & Tall pier & 2.39 & -9938 & 5758 & 33138 & 1.29 & -9928 & 61479 \\
\hline & $\begin{array}{l}\text { Short } \\
\text { pier }\end{array}$ & 2.39 & -8986 & 5739 & 33128 & 1.29 & -9928 & 61479 \\
\hline & $\begin{array}{c}\text { Increase } \\
\%\end{array}$ & 0.00 & 11 & 0 & 0 & 0 & 0 & 0 \\
\hline \multirow{3}{*}{3} & Tall pier & 1.42 & -13136 & 26163 & 27282 & 0.72 & -9025 & 156479 \\
\hline & $\begin{array}{l}\text { Short } \\
\text { pier }\end{array}$ & 1.33 & -16638 & 27949 & 26742 & 0.68 & -8957 & 169576 \\
\hline & $\begin{array}{c}\text { Increase } \\
\%\end{array}$ & 7.00 & -21 & -6 & 2 & 6 & 1 & -8 \\
\hline
\end{tabular}

The opposite occurs for the bending moment in the pylon, because the moments are bigger for the case of a short pier than for the case of the tall pier. For type 2 connection, the contribution of the height pier is null in the behaviour of the five-span bridge because the deck is separated from the influence of the pier; that is, the deck rotates around its supports. For a type 3 connection, the differences in the behaviour of the bridge of five spans are accentuated for the type 1 connection because, for the tall pier, the embedding between deck and pier-pylon favours their behaviour. When the height of the pier is $60 \%$ the height of the pylon or more, the deflection of the pier is considerably reduced. Table 3 shows a comparison of the values obtained for the bridge models of five spans with short and tall piers. It is noticed that the mechanical elements and deformations in both deck and pylons result with the same values between connections type 1 and 3. The explanation of this phenomenon is previously discussed in Section 5.1 that present the same behaviour. 


\section{Conclusions}

The behaviour of a multi-span cable-stayed bridge under alternate live loads was analysed by changing the stiffness of their elements. A parametric analysis of mathematical models of bridges with three and five spans was carried out. The following conclusions are presented:

1. In multi-span cable-stayed bridges, the harp cable system has advantages over the fan type when both alternate live loads and the same stiffness values of deck and pier-pylon are presented. It has also been demonstrated that the pier-pylon element provides an important part of the resistant mechanism of multi-span cablestayed bridges for both systems (harp and fan).

2. For the three types of connection between pier-pylon and deck, both the stresses and deformations in the elements are higher in multi-span cable-stayed bridges due to the lack of cables anchored to fixed points.

3. For connection type 1 , it is necessary to increase six times the pier-pylon stiffness when a short pier is used and up to ten times for the case of the tall pier to improve the deck behaviour of a multi-span cable-stayed bridge for obtaining a similar efficiency to a three-span bridge. It is necessary to increase three times the deck stiffness in the case of a short pier, and nine times in the case of the tall pier to obtain a deck behaviour of a multi-span cablestayed bridge similar to the three-span bridge.

4. For the case of type 2 connection, obtaining a multi-span bridge with similar efficiency to a three-span bridge is impractical: an increase of ten times in the deck stiffness is necessary for the case of a short pier, whereas for the case of the tall pier, a deck stiffness of thirty-four times is required.

5. In the type 3 connection, to improve deck behaviour of multispan cable-stayed bridge as a three-span bridge, it is necessary to increase the pier-pylon stiffness in six times for the case of the tall pier, and five times for the case of a short pier, because the elements are embedded. In types 1 and 3, the increase in pier height adversely affects the behaviour of the multi-span cable-stayed bridge, but for type 2 , the contribution of the height pier is null in the behaviour, making type 2 connection satisfactory for remarkable pier heights.

6. The results allow the identification of the most suitable configuration for the design of a multi-span cable-stayed bridge considering the cable system, pier-pylon and deck stiffness, and type of connection between the elements.

7. It is recommended to improve this study by taking into account other configurations of multi-span cable-stayed bridges, for
Parametric Analysis

of Multi-Span

Cable-Stayed

Bridges under

Alternate Loads 
example, bridges with seven or ten continuous spans or bridges with different span lengths. Moreover, it is convenient to considerer the influence of the different type of connections between pier-pylon and deck.

8. It is necessary to consider different configurations of alternating live loads, to calculate the cable cross-sections, to study the possibility to reduce deflections of the deck as well as to redistribute the bending moments in the elements to improving the proposed parametric analysis.

\section{Acknowledgements}

The first author, thanks to Consejo Nacional de Ciencia y Tecnología (CONACYT) for the scholarship granted to complete his PhD studies. The third author thanks Universidad Autónoma Metropolitana.

\section{Disclosure Statement}

The authors declare that they have not competed for financial, professional and personal interests from other parties.

\section{REFERENCES}

Agrawal, T. P. (1997). Cable-stayed bridges-parametric study. Journal of bridge engineering, 2(2), 61-67.

https://doi.org/10.1061/(ASCE)1084-0702(1997)2:2(61)

Amiri, I., \& Nakamura, S. (2015). Comparative Study on Multi-Span Cable-Stayed Bridges with Hybrid, RC and Steel Towers, in Proceedings of the School of Engineering Tokai University Series E 40, vol. XXI (pp.29-36).

Arnaud, S., Matsunaga, N., Nagano, S., \& Ragaru, J. (2008). Behavior of a multiple spans cable-stayed bridge, in J. Walraven, D. Stoelhorst, (Eds) Tailor Made Concrete Structures: New Solutions for our Society (pp.807-813).

Camara, A., \& Efthymiou, E. (2016). Deck-tower interaction in the transverse seismic response of cable-stayed bridges and optimum configurations. Engineering Structures, 124, 494-506.

https://doi.org/10.1016/j.engstruct.2016.06.017

Chen, D. W., Au, F. T. K., Tham, L. G., \& Lee, P. K. K. (2000). Determination of initial cable forces in prestressed concrete cable-stayed bridges for given design deck profiles using the force equilibrium method. Computers \& Structures, 74(1), 1-9. https://doi.org/10.1016/S0045-7949(98)00315-0

EN 1991-2:2003. Eurocode 1: Actions on Structures - Part 2: Traffic Loads on Bridges 
Hegab, H. I. (1986). Energy analysis of cable-stayed bridges. Journal of Structural Engineering, 112(5), 1182-1195. https://doi.org/10.1061/(ASCE)0733-9445(1986)112:5(1182)

Hegab, H. I. (1988). Parametric investigation of cable-stayed bridges. Journal of Structural Engineering, 114(8), 1917-1928. https://doi.org/10.1061/(ASCE)0733-9445(1988)114:8(1917)

Krishna, P., Arya, A. S., \& Agrawal, T. P. (1985). Effect of cable stiffness on cable-stayed bridges. Journal of Structural Engineering, 111(9), 2008-2020. https://doi.org/10.1061/(ASCE)0733-9445(1985)111:9(2008)

Mozos, C. M., \& Aparicio, A. C. (2010a). Parametric study on the dynamic response of cable stayed bridges to the sudden failure of a stay, Part I: Bending moment acting on the deck. Engineering Structures, 32(10), 3288-3300. https://doi.org/10.1016/j.engstruct.2010.07.003

Mozos, C. M., \& Aparicio, A. C. (2010b). Parametric study on the dynamic response of cable stayed bridges to the sudden failure of a stay, Part II: Bending moment acting on the pylons and stress on the stays. Engineering Structures, 32(10), 3301-3312. https://doi.org/10.1016/j.engstruct.2010.07.002

O'Connor, C. (1971). Design of Bridge Superstructures (1st ed.). Wiley-Interscience.

Scalzi, J. B., \& Podolny, W. (1976). Construction and design of cable-stayed bridges. Wiley-Interscience.

Secretaría de Comunicaciones y Transportes (SCT) (2001). Normativa para la infraestructura del transporte. Norma oficial mexicana (In Spanish)

Service d'Etudes Techniques des Routes et Autoroutes SETRA (2001). Haubans Recommandations de la Commission Interministérielle de la Précontrainte, Ministère de L'équipement des Transports et du Logement, France (In French)

Straupe, V., \& Paeglitis, A. (2012). Analysis of interactions between the elements in cable-stayed bridge, The Baltic Journal of Road and Bridge Engineering, 7(2), 84-91. https://doi.org/10.3846/bjrbe.2012.12

Straupe, V., \& Paeglitis, A. (2013). Analysis of geometrical and mechanical properties of cable-stayed bridge. Procedia Engineering, 57, 1086-1093. https://doi.org/10.1016/j.proeng.2013.04.137

Virlogeux, M. (2001). Bridges with multiple cable-stayed spans. Structural Engineering International, 11(1), 61-82. https://doi.org/10.2749/101686601780324250

Wang, H., Chen, C., Xing, C., \& Li, A. (2014). Influence of structural parameters on dynamic characteristics and wind-induced buffeting responses of a super-long-span cable-stayed bridge. Earthquake Engineering and Engineering Vibration, 13(3), 389-399. https://doi.org/10.1007/s11803-014-0250-0

Wang, P. H., \& Yang, C. G. (1996). Parametric studies on cable-stayed bridges. Computers \& Structures, 60(2), 243-260. https://doi.org/10.1016/0045-7949(95)00382-7

Zong, Z. H., Zhou, R., Huang, X. Y., \& Xia, Z. H. (2014). Seismic response study on a multi-span cable-stayed bridge scale model under multi-support excitations. Part I: shaking table tests. Journal of Zhejiang University SCIENCE A, 15(5), 351-363. https://doi.org/10.1631/jzus.A1300339 